\title{
Pecan Kernel Color: Standards Using the Munsell Color Notation System
}

\author{
Tommy E. Thompson, L.J. Grauke, and E.F. Young, Jr. \\ Pecan Genetics and Improvement Research, Agricultural Research Service, U.S. Department of Agriculture, \\ Route 2, Box 133, Somerville, TX 77879
}

Additional index words. Carya illinoinensis, nut quality

\begin{abstract}
The Munsell Color System was used to define pecan [Carya illinoinensis (Wangenh.) K. Koch] kernel colors and color changes for 21 clones, 11 locations, and 4 storage methods for nuts collected over a 4-year period. Hue readings ranged from 10.0 (10 red) to 22.5 ( 2.5 yellow). Value readings ranged from 2.5 to 8.0, and chroma readings ranged from 1.0 to 8.0. A total of 91 color chips (individual combinations of hue, value, and chroma) were needed to describe kernel color variability. In 1987 and 1988, one color [15.0/5/4 (hue/value/chroma)] accounted for 3,979 of the 32,078 readings taken, and the 15 most common colors accounted for $80.7 \%$ of all the readings. The Munsell system of color determination was well suited for pecan color determinations. A simplified color rating system with only six color classes was developed for general use by the pecan industry. This system is also routinely used in our breeding and genetics program to define this very important quality trait in pecan.
\end{abstract}

Various classification systems have been used to describe kernel color in pecan (Carya illinoinensis). The U.S. Dept. of Agriculture (USDA) developed a four color standard based on color classes of golden, light brown, medium brown, and dark brown [Agricultural Marketing Service (AMS), 1976]. Rubber models (Pec-MC-1-1968), developed by the USDA, represent the four standard colors. This system is largely ignored by the industry, possibly because high quality pecans are lighter in color than golden and are not represented. Other systems of pecan kernel color description have arisen within sections of the pecan industry. These systems use different color names and have no defined, reproducible color standards. In Texas, a five-class system has been widely used (McEachern et al., 1994). The system relies on a photograph of five kernels, each representing a color class. Unfortunately, the system is not defined by uniform color notation and accurate photographic reproduction is a problem. In comparing color prints produced from the same negative for different years, there are obvious color differences from picture to picture for the same kernel half.

In the pecan industry, kernel color is the main indicator of freshness and quality, with dark color indicating age and rancidity. The USDA defines kernels as damaged when they are dark amber in color. Dark amber means that $>25 \%$ of the outer surface of the kernel is dark brown, with not $>25 \%$ - darker than dark brown (AMS, 1976). The dark brown classification is determined by comparing kernels with standard rubber kernel models. Kernels that are affected by a dark brown or yellowish-orange discoloration which extends into the flesh are rancid to the taste (National Pecan Growers Council, 1980).

Many factors affect the rate and level of color development in pecan, including cultivar (Forbus et al, 1983; Heaton et al., 1975; Kays and Wilson, 1978), time of harvest (Heaton et al., 1975; Kays and Wilson, 1977), percent moisture in the kernel (Heaton and Woodroof, 1970), time in storage (Forbus et al., 1983; Kays and

Received for publication 31 July 1995. Accepted for publication 14 Dec. 1995. Names are necessary to report factually on available data; however, the USDA neither guarantees nor warrants the standard of the product, and the use of the name by USDA implies no approval of the product to the exclusion of others that may also be suitable. The cost of publishing this paper was defrayed in part by the payment of page charges. Under postal regulations, this paper therefore must be hereby marked advertisement solely to indicate this fact.
Wilson, 1978), and whether stored shelled or in-shell (Kays and Wilson, 1978). Postharvest hot water, steam, and dielectric heating treatments may also affect kernel color (Forbus et al., 1983; Senter et al., 1984).

Several techniques have been used by scientists to study pecan kernel colors. Hunter colorimeter instruments (Hunter Assoc., Reston, Va.) were used by Kays and Wilson (1977), Forbus et al. (1983), and Senter et al. (1984). Gardner color difference meters have also been used (Heaton et al., 1975 and Kays, 1977). McGuire (1992) gave an excellent review of what these various readings mean and how they are often misused in determining treatment differences. The Hunter and Gardner instruments correctly determine lightness (L). However, two other instrument coordinates (a and b) are related, and only indirectly reflect the visually informative parameters of hue and chroma. They are difficult to interpret separately. Usually hue and chroma are not calculated from these values, so important information is sometimes not analyzed properly (McGuire, 1992).

Visual ratings of an object by comparison with color chips can be as accurate as instrument readings. For example, strawberry fruit color was determined both subjectively [single observer using color chips from a color specifier (747xR; Pantone, Moonachie, N.J.)] and also objectively using a Colormet reflectance spectrophotometer (Agtron, Reno, Nev.) (Shaw, 1991). Similar experimental precision was obtained with both methods.

Conrad et al. (1987) studied product color in tabasco pepper sauce using the Munsell system of color. (Macbeth; Kollmorgan Instruments Corp., Baltimore) as the correct standard, and testing both the Gardner Color Difference Meter and the approved method of the Association of Official Chemists (AOAC) against this standard.

In the National Pecan Breeding Program, we needed a highly efficient, rapid, and portable system of kernel color determination. The Munsell system was selected based on the above criteria, plus its widespread usage, low cost, and easy availability. We also considered the Centroid system (Kelly and Judd, 1955; Kelly, 1965). It is a less well recognized system that utilizes a much more cumbersome system of notation. The Munsell notation is decimal and can be refined to any degree necessary. It is also easily converted to a continuous numeric scale for statistical analysis. The Munsell system is accepted as a standard by the scientific community (ASTM, 1989). The Inter-Society Color Council and 
Table 1. The number of kernel color ratings made on different cultivars at different locations in 1987 and 1988.

\begin{tabular}{|c|c|c|c|c|c|c|c|c|}
\hline Cultivar & Year & $\begin{array}{c}\text { El Paso, } \\
\text { Texas }\end{array}$ & $\begin{array}{c}\text { Tulare, } \\
\text { Calif. }\end{array}$ & $\begin{array}{c}\text { Brown- } \\
\text { wood, } \\
\text { Texas }\end{array}$ & $\begin{array}{c}\text { Crystal } \\
\text { City, } \\
\text { Texas }\end{array}$ & $\begin{array}{c}\text { Weslaco, } \\
\text { Texas }\end{array}$ & $\begin{array}{c}\text { Tifton, } \\
\text { Ga. }\end{array}$ & $\begin{array}{c}\text { Cultivar } \\
\text { totals }\end{array}$ \\
\hline \multirow[t]{2}{*}{ Cheyenne } & 87 & 660 & 660 & 666 & 660 & 660 & 0 & \\
\hline & 88 & 656 & 652 & 661 & 660 & 660 & 660 & 7,255 \\
\hline \multirow[t]{2}{*}{ Choctaw } & 87 & 663 & 661 & 652 & 660 & 660 & 0 & \\
\hline & 88 & 661 & 660 & 660 & 660 & 660 & 660 & 7,257 \\
\hline \multirow[t]{2}{*}{ Sioux } & 87 & 610 & 661 & 610 & 603 & 0 & 0 & \\
\hline & 88 & 657 & 0 & 660 & 660 & 660 & 0 & 5,121 \\
\hline \multirow[t]{2}{*}{ Western } & 87 & 658 & 658 & 666 & 657 & 0 & 677 & \\
\hline & 88 & 660 & 660 & 650 & 663 & 138 & 663 & 6,750 \\
\hline \multirow[t]{2}{*}{ Wichita } & 87 & 656 & 660 & 660 & 416 & 0 & 660 & \\
\hline & 88 & 660 & 660 & 660 & 660 & 0 & 660 & 6,352 \\
\hline Totals & & 6,541 & 5,932 & 6,545 & 6,299 & 3,438 & 3,980 & 32,735 \\
\hline
\end{tabular}

the National Bureau of Standards use the notation to specify colorname limits in the ISCC-NBS Method of Designating Color (Kelly, 1965). Possibly the highest recommendation for the use of this system comes from the National Cooperative Soil Survey (Soil Survey Division Staff, 1993). Soil scientists throughout the United States routinely use Munsell Soil Color Charts for field determinations of soil color.

Three aspects of perceived color are directly determined with the Munsell system of color. These are value (lightness from black to white on a scale of 0 to 10), chroma (degree of departure from gray toward pure chromatic color), and hue (red, orange, yellow, green, etc.). The purpose of this report is to l) describe the range of pecan kernel color variability using the Munsell Color System, 2) to propose a systematic scale to describe that variability, and 3) to associate standard color names to the designated scale.

\section{Materials and Methods}

In 1985 and 1986, preliminary experiments were conducted by collecting a large number of nut samples of different genotypes from across the United States pecan belt. The clean, dry (about 4\% moisture) nuts were stored on lab benches in natural light at room temperature until analyses were begun in February of the following years. For some genotypes, additional samples were cracked every 2 months for up to five cracking dates.

Kernel color readings were recorded at the time of cracking by comparing their color with the Munsell soil color chips (Macbeth; Kollmorgan Instruments Corp., Baltimore). After cracking, kernels were stored (in natural light) on lab benches. These shelled kernels were also rated on subsequent cracking dates (about every 2 months) to compare color changes of shelled and unshelled kernels. Based on these preliminary observations, a 2-year test was planned.

In the fall of 1987 and 1988, as cultivars matured at six locations across the United States (Table 1), nine 10-nut samples of each genotype at each location were collected and stored on the lab bench at El Paso, Texas. In January of the 2 following years, two of the samples of each genotype were stored at -5C. Quality determinations of the seven remaining samples stored at room temperature were also begun at this time with one sample of each genotype from each location being shelled by hand after cracking individual nuts with an inertia cracker. Day 0 for the initiation of the analysis of the 1987 crop nuts was 8 Jan. 1988 and for the 1988 crop nuts was 20 Jan. 1989. These kernels were rated for kernel color as described below, and were stored on the lab bench at 20 to
24C with normal diurnal light cycles (natural light entering lab via windows) until the next reading. Additional nut samples were cracked at two month intervals through January of the following years, giving seven shelling and rating dates for each year.

One of the frozen samples was thawed, shelled, and rated after six months, and the other sample was analyzed at the end of 1 year.

After shelling, kernel halves were sorted into three groups: plump kernels, thin wafer kernels, and diseased kernels. Only the ratings for plump kernels are included in this report.

The dorsal side of the kernel with the apex pointed to the right was used for kernel color determination. The best color fit (determination) was obtained from the upper shoulder of the right-half of the kernel. Lighting and viewing conditions in the laboratory were as recommended in standard test methods (ASTM, 1989).

The 10 red; the 2.5, 5.0, 7.5, and 10 yellow-red; and the 2.5 yellow hues were used to define all kernel colors. These hues can also be expressed numerically to give a continuous range from 10.0

Table 3. Frequency and percent of pecan kernel color readings made in 1987 and 1988 using Munsell hue, value, and chroma standards.

\begin{tabular}{lrrr}
\hline \hline Color & Level & Frequency & Percent \\
\hline Hue & 10.0 & 7,624 & 23.8 \\
& 12.5 & 8,048 & 25.1 \\
& 15.0 & 9,190 & 28.6 \\
& 17.5 & 4,952 & 15.4 \\
Total & 20.0 & 2,228 & 6.9 \\
Value & 22.5 & 36 & 0.1 \\
& & 32,078 & \\
& 2.5 & 4 & 0.0 \\
& 3.0 & 806 & 2.5 \\
& 4.0 & 6,660 & 20.8 \\
Total & 5.0 & 15,383 & 48.0 \\
Chroma & 6.0 & 8,048 & 25.1 \\
& 7.0 & 958 & 3.0 \\
& 8.0 & 219 & 0.7 \\
& & 32,078 & \\
& 1 & 3 & 0.0 \\
& 2 & 24 & 0.1 \\
Total & 3 & 2,854 & 8.9 \\
& 4 & 23,056 & 71.9 \\
& 6 & 6,017 & 18.8 \\
& 8 & 124 & 0.4 \\
& & 32,078 & \\
\hline
\end{tabular}


Table 4. Pecan kernel color variability within experimental classes averaged for 1987 and 1988.

\begin{tabular}{|c|c|c|c|c|c|c|c|}
\hline \multirow[b]{2}{*}{ Frequency } & \multirow[b]{2}{*}{ Frequency } & \multicolumn{2}{|c|}{ Hue } & \multicolumn{2}{|c|}{ Value } & \multicolumn{2}{|c|}{ Chroma } \\
\hline & & Mean & SD & Mean & SD & Mean & SD \\
\hline \multicolumn{8}{|l|}{ Genotype } \\
\hline Cheyenne & 7,082 & 15.30 & 2.97 & 5.40 & 0.88 & 4.44 & 0.93 \\
\hline Choctaw & 6,756 & 14.02 & 2.93 & 4.99 & 0.84 & 4.09 & 0.77 \\
\hline Sioux & 5,118 & 14.24 & 3.04 & 5.27 & 0.80 & 4.25 & 0.87 \\
\hline Western & 6,187 & 13.58 & 2.80 & 4.99 & 0.75 & 4.31 & 0.88 \\
\hline Wichita & 6,310 & 12.49 & 2.65 & 4.77 & 0.84 & 4.44 & 1.00 \\
\hline Mohawk & 625 & 12.73 & 2.31 & 4.55 & 0.81 & 3.96 & 0.58 \\
\hline \multicolumn{8}{|l|}{ Location } \\
\hline El Paso, Texas & 6,030 & 14.53 & 3.12 & 5.25 & 0.89 & 4.44 & 0.99 \\
\hline Tulare, Calif. & 5,428 & 13.4 & 2.91 & 4.78 & 0.83 & 4.25 & 0.86 \\
\hline Brownwood, Texas & 6,289 & 14.18 & 3.14 & 5.27 & 0.73 & 4.26 & 0.87 \\
\hline Crystal City, Texas-1 & 6,172 & 13.93 & 3.02 & 5.11 & 0.90 & 4.23 & 0.81 \\
\hline Crystal City, Texas-2 & 662 & 14.83 & 3.06 & 5.02 & 0.93 & 4.63 & 1.11 \\
\hline Weslaco, Texas & 3,674 & 13.65 & 2.72 & 5.00 & 0.81 & 4.13 & 0.79 \\
\hline Tifton, Ga. & 3,183 & 12.93 & 2.56 & 4.82 & 0.80 & 4.30 & 0.93 \\
\hline Byron, Ga. & 640 & 15.85 & 2.71 & 5.20 & 0.83 & 5.05 & 1.04 \\
\hline \multicolumn{8}{|l|}{ Year } \\
\hline 1987 & 15,423 & 14.85 & 3.09 & 5.03 & 0.96 & 4.68 & 1.04 \\
\hline 1988 & 16,655 & 13.07 & 2.68 & 5.11 & 0.75 & 3.95 & 0.56 \\
\hline \multicolumn{8}{|l|}{ Storage (inshell) } \\
\hline Control (fresh) & 943 & 18.39 & 1.91 & 5.98 & 0.78 & 4.75 & 1.08 \\
\hline 6 Months/23C & 1,985 & 16.20 & 2.69 & 5.61 & 0.80 & 4.62 & 0.95 \\
\hline 12 Months/23C & 1,994 & 14.98 & 3.18 & 5.64 & 0.77 & 3.88 & 0.48 \\
\hline 6 Months/-5C & 3,872 & 15.37 & 2.85 & 5.47 & 0.78 & 4.27 & 0.86 \\
\hline 12 Months/-5C & 969 & 17.28 & 2.19 & 6.10 & 0.65 & 3.90 & 0.50 \\
\hline
\end{tabular}

for 10R to 22.5 for $2.5 \mathrm{Y}$ (Munsell 100 hue circuit). These readings were used throughout this study since this facilitated statistical analyses.

\section{Results and Discussion}

The 1987 and 1988 test identified the Munsell color classes needed to define essentially all color variability in pecan. Overall, $80.7 \%$ of the individual readings were defined as being limited to 15 classes (Table 2). Breaking this down further into major parts of this 2-year study, in excess of $92 \%$ of the readings in four major treatments (stored inshell at room temperature (20 to 24C) for 6 months, stored inshell at room temperature for 12 months, stored at $-5 \mathrm{C}$ for 6 months, and stored at $-5 \mathrm{C}$ for 12 months) consisted of the 15 most common classes.

As indicated in the preliminary test, hue levels needed to define color for the entire test ranged from 10.0 (10 red) to 22.5 (2.5 yellow) (Table 3). Three levels of hue readings (10.0, 12.5, and 15.0) each contained about one-quarter of the total readings. Very few $(0.1 \%)$ of the readings were in the highest numeric level $(22.5$ or 2.5 yellow).

Value readings with the Munsell system are especially interesting since this reading denotes lightness or darkness of any color. Pecan kernel quality is traditionally determined by subjectively evaluating lightness or darkness. Values ranged from 2.5 to 8 , with almost half of the class values being 5 . The desire to have a simple color system that consists only of the value reading, while ignoring hue and chroma, was investigated. This proved to be inadequate for quality definition. For instance, there seems to be differences in quality of kernels with different hue readings, but the same value.

The same is true to some extent with chroma. A hue of 2.5 yellow (22.5) can be almost gray (chroma 2) or a much more golden yellow (chroma 8) at the higher values. Also, too much red [e.g., 10R(10.0)] denotes aged kernels while more yellow classes with the same value and chroma are acceptable.

Whether the Munsell Color System was sufficient to define variability within genotypes, locations, years, and storage treatments was determined (Table 4). There was adequate variability in readings for hue, value, and chroma to define color in kernels in all cultivars and stages of decay.

Considerable time was spent formulating a practical system for rapid routine kernel color classification using the Munsell system. The frequency of different color classes was considered (Fig. 1). The relative levels of hue, value, and chroma in defining color were questioned, and compared with actual kernels of differing colors. A six-class Munsell color system (Table 5) was developed, mainly from trial-and-error manipulation of data in Fig. 1. Note here that the horizontal continuum is by value, hue, then chroma. Frequency of use of the different chips was of some consideration in choosing these representative six chips. Note that each class has a different value from lightest (8) to darkest (3). There is also an associated

Table 5. Munsell color chips needed to classify pecan kernel color.

\begin{tabular}{lcccc}
\hline \hline Class & Class name & Hue & Value & Chroma \\
\hline 1 & Light cream & $22.5(2.5 \mathrm{Y})$ & 8 & 4 \\
2 & Cream & $20.0(10 \mathrm{YR})$ & 7 & 4 \\
3 & Golden & $17.5(7.5 \mathrm{YR})$ & 6 & 4 \\
4 & Light brown & $15.0(5 \mathrm{YR})$ & 5 & 4 \\
5 & Reddish brown & $12.5(2.5 \mathrm{YR})$ & 4 & 4 \\
6 & Dark reddish brown & $10.0(10 \mathrm{R})$ & 3 & 4 \\
\hline
\end{tabular}




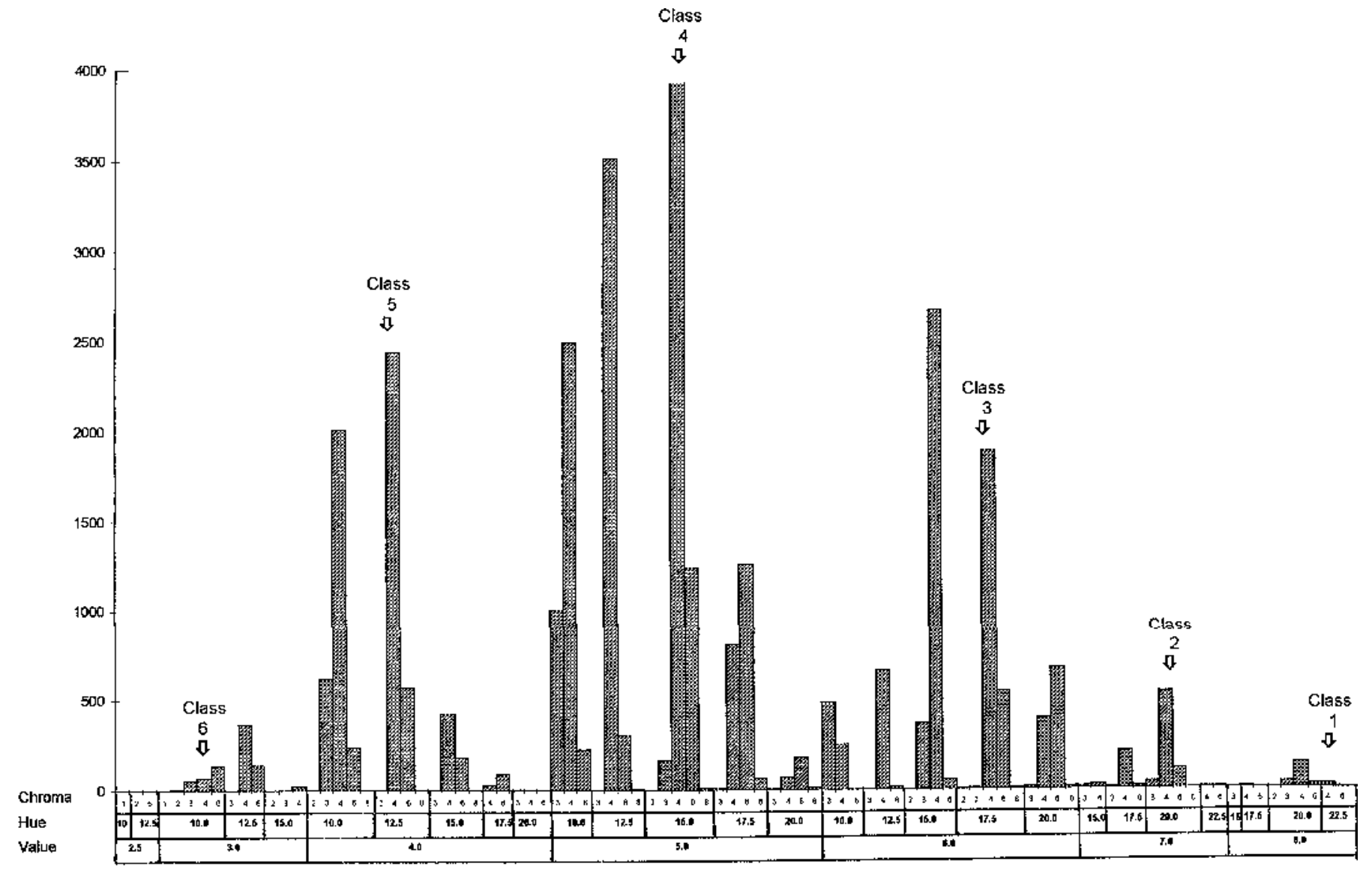

Fig. 1. Frequency of pecan kernel color readings by value, hue, and chroma; showing position of six classes chosen to represent major color classes.

Table 6. Munsell color classification of the USDA pecan color models (Pec-MC-1-1968).

\begin{tabular}{lc}
\hline \hline $\begin{array}{l}\text { USDA } \\
\text { color name }\end{array}$ & $\begin{array}{c}\text { Munsell color } \\
\text { (hue/value/chroma) }\end{array}$ \\
\hline Golden & $17.5 / 5 / 6$ \\
Light brown & $15.0 / 4 / 6$ \\
Medium brown & $12.5 / 4 / 4$ \\
Dark brown & $12.5 / 3 / 2$ \\
\hline
\end{tabular}

uniform decline in hue levels (yellow to red). Chroma made little difference and readings of 4 were used (most common as discussed above).
It is important to point out that this six-class system does not define class limits precisely in terms of Munsell hue, value, and chroma. For instance, no attempt was made to classify the 91 Munsell chips into this six-class system. Also, value alone is not sufficient to determine class, as Fig. 1 might suggest. This system is meant to be used by matching the kernel to the closest of the six Munsell chips, and that class is assigned.

The four USDA kernel color standards (Pec-MC-1-1968) have been used very little in the pecan industry, since the classes mainly define extremely poor quality kernels. Even the best color (golden) is not highly desirable in the pecan industry. We classified the four colored models of this system using the Munsell system (Table 6). We consider this system inadequate.

We investigated the use of the Centroid system to define pecan

Table 7. Class names and hue/value/chroma definition from ISCC-NBS color designations and the Munsell system.

\begin{tabular}{|c|c|c|c|c|c|}
\hline \multirow[b]{2}{*}{ Class } & \multicolumn{2}{|c|}{ Munsell } & \multicolumn{3}{|c|}{ ISCC-NBS Centroid color designation } \\
\hline & $\mathrm{H} / \mathrm{V} / \mathrm{C}^{\mathrm{z}}$ & $\begin{array}{c}\text { Soil color } \\
\text { name }\end{array}$ & $\begin{array}{l}\text { Centroid } \\
\text { chip no. }\end{array}$ & $\begin{array}{l}\text { Color } \\
\text { name }\end{array}$ & $\begin{array}{l}\text { Munsell } \\
\text { renotation }\end{array}$ \\
\hline$\overline{1}$ & $2.5 \mathrm{Y} / 8 / 4$ & Pale yellow & 89 & Pale yellow & $4.7 \mathrm{Y} / 9.0 / 3.8$ \\
\hline 2 & $10 \mathrm{YR} / 7 / 4$ & Very pale brown & 76 & Light yellow brown & 8.7YR/6.5/5.0 \\
\hline 3 & $7.5 \mathrm{YR} / 6 / 4$ & Light brown & 33 & Brownish pink & 7.0YR/7.1/2.3 \\
\hline 4 & $5 \mathrm{YR} / 5 / 4$ & Reddish brown & 57 & Light brown & $5.4 \mathrm{YR} / 5.4 / 4.8$ \\
\hline 5 & $2.5 \mathrm{YR} / 4 / 4$ & Reddish brown & 43 & Medium reddish brown & $9.0 \mathrm{R} / 3.4 / 5.0$ \\
\hline 6 & $10 \mathrm{R} / 3 / 4$ & Dusky red & 44 & Dark reddish brown & $9.6 \mathrm{R} / 1.3 / 3.6$ \\
\hline
\end{tabular}


Table 2. Frequency $(\mathrm{F})$ of the 15 most common Munsell hue (H), value (V), and chroma (C) classes for pecan kernels from 1987 and 1988 crop years.

\begin{tabular}{|c|c|c|c|c|c|c|c|c|c|c|c|c|c|c|}
\hline \multicolumn{5}{|c|}{ Overall } & \multicolumn{5}{|c|}{ Inshell (6 months) } & \multicolumn{5}{|c|}{ Inshell (12 months) } \\
\hline$\underline{\mathrm{H}}$ & $\mathrm{V}$ & $\mathrm{C}$ & $\mathrm{F}$ & $\%$ & $\mathrm{H}$ & V & $\mathrm{C}$ & $\mathrm{F}$ & $\%$ & $\mathrm{H}$ & $\mathrm{V}$ & $\mathrm{C}$ & $\mathrm{F}$ & $\%$ \\
\hline 15 & 5 & 4 & 3,979 & 12.4 & 20 & 6 & 6 & 161 & 17.1 & 15 & 5 & 4 & 161 & 15.8 \\
\hline 12.5 & 5 & 4 & 3,519 & 11 & 17.5 & 6 & 4 & 139 & 14.7 & 12.5 & 5 & 4 & 160 & 15.7 \\
\hline 15 & 6 & 4 & 2,673 & 8.3 & 20 & 6 & 4 & 96 & 10.2 & 15 & 6 & 4 & 107 & 10.5 \\
\hline 10 & 5 & 4 & 2,502 & 7.8 & 15 & 6 & 4 & 92 & 9.8 & 17.5 & 5 & 6 & 95 & 9.3 \\
\hline 12.5 & 4 & 4 & 2,447 & 7.6 & 17.5 & 5 & 6 & 74 & 7.8 & 15 & 5 & 6 & 71 & 7 \\
\hline 10 & 4 & 4 & 2,010 & 6.3 & 20 & 7 & 4 & 66 & 7 & 17.5 & 6 & 4 & 63 & 6.2 \\
\hline 17.5 & 6 & 4 & 1,891 & 5.9 & 20 & 5 & 6 & 45 & 4.8 & 17.5 & 5 & 4 & 61 & 6 \\
\hline 17.5 & 5 & 6 & 1,271 & 4 & 17.5 & 5 & 4 & 44 & 4.7 & 10 & 5 & 4 & 50 & 4.9 \\
\hline 15 & 5 & 6 & 1,250 & 3.9 & 17.5 & 6 & 6 & 35 & 3.7 & 17.5 & 6 & 6 & 40 & 3.9 \\
\hline 10 & 5 & 3 & 1,011 & 3.2 & 15 & 5 & 4 & 31 & 3.3 & 12.5 & 4 & 4 & 36 & 3.5 \\
\hline 17.5 & 5 & 4 & 810 & 2.5 & 20 & 8 & 4 & 28 & 3 & 12.5 & 6 & 4 & 25 & 2.5 \\
\hline 20 & 6 & 6 & 669 & 2.1 & 20 & 7 & 6 & 23 & 2.4 & 12.5 & 4 & 6 & 18 & 1.8 \\
\hline 12.5 & 6 & 4 & 667 & 2.1 & 15 & 6 & 3 & 21 & 2.2 & 12.5 & 5 & 6 & 17 & 1.7 \\
\hline 10 & 4 & 3 & 623 & 1.9 & 17.5 & 7 & 4 & 17 & 1.8 & 20 & 7 & 4 & 16 & 1.6 \\
\hline 12.5 & 4 & 6 & 576 & 1.8 & 20 & 5 & 4 & 16 & 1.7 & 15 & 6 & 6 & 16 & 1.6 \\
\hline Totals $^{\mathrm{z}}$ & & & 32,078 & & & & & 943 & & & & & 1,017 & \\
\hline Percent $^{\mathrm{y}}$ & & & & 80.7 & & & & & 94.2 & & & & & 92 \\
\hline
\end{tabular}

zTotals refer to entire databases, not just the 15 classes listed here.

yPercentages represent the fifteen color classes given here, as a proportion of the total for that class.

kernel color. In this system, color space is arbitrarily divided into blocks, each of which is given a standardized color name. The color chips representing the six pecan color classes were visually matched with the Centroid color chips (Table 7). The resolution within this Centroid color system was inadequate, and recommended color names (e.g., brownish pink) were inappropriate for use in the pecan industry.

The possible adoption of the names of Munsell color chips used by soil scientists was also investigated. These names lacked specificity, since two points on the pecan kernel color scale had the same name.

Whether colors generated on personal computer screens and printers could be used as standardized pecan colors was of interest. Obvious limitations here include differences between transmitted and reflected light, lack of standardization across the computer industry, and the inability of computers to generate needed colors. See Sugihara (1995) for a review.

To summarize, the variability of pecan kernel color is accurately described using 91 chips of the Munsell Color system in the yellow to red range. For studies requiring maximum resolution, six pages of the Munsell Soil Color Charts (hue sheets 2.5Y, 10YR, 7.5YR, 5YR, 2.5YR, and 10R) provide an inexpensive, accessible, portable, and very accurate system of pecan kernel color determination. This system is recommended for scientific studies where maximum color definition is required.

A six class rating scale has been developed that systematically divides the range of hues by uniformly decreasing value as hue changes from yellow to red, at a common chroma. Standard color names are recommended for each of the six color classes, based on current practices of the pecan industry. Compared to the electronic instruments, the advantages of this system are the reduced cost of standard acquisition, the increased speed of rating kernels, and the standardization of color names. Compared to alternative photographic standards, this system has the advantage of reproducibility. The six class rating system will be used exclusively throughout the USDA/ARS Pecan Breeding Program, which conducts production tests in all major pecan production areas of the United States.

\section{Literature Cited}

Agricultural Marketing Service. 1976. United States standards for grades of pecans in the shell. Agr. Mkt. Serv. (FR Doc. 76-26886).

American Society for Testing and Materials. 1989. Standard test method for specifying color by the Munsell system. Annual book of ASTM standards D 1535-89. Amer. Soc. for Testing and Materials, Philadelphia.

Conrad, R.S., F.J. Sundstrom, and P.W. Wilson. 1987. Evaluation of two methods of pepper fruit color determination. HortScience 22:608-609.

Forbus, Jr., W.R., S.D. Senter, and R.L. Wilson. 1983. Cultivar, processing, and storage effects on pecan kernel color. J. Food Sci. 48(6):16461649.

Heaton, E.K. and J.G. Woodroof. 1970. Humidity and weight loss in cold stored pecans. Amer. Soc. Heating, Refrig. Air-Cond. Eng. J. 12(4):4951.

Heaton, E.K., R.E. Worthington, and A.L. Shewfelt. 1975. Pecan nut quality. Effect of time of harvest on composition, sensory, and quality characteristics. J. Food Sci. 40:1260-1263.

Kays, S.J. 1977. Influence of the nut's internal oxygen partial pressure on the induction of pigmentation in the kernels of pecan. J. Amer. Soc. Hort. Sci. 102:531-533.

Kays, S.J. and D.M. Wilson. 1977. Chronological sequence of pigment development in the kernels of pecan, Carya illinoensis (Wang.) K. Koch, c.v. Stuart. Scientia Hort. 6:213-222.

Kays, S.J. and D.M. Wilson. 1978. Genotype variation in pecan kernel color and color stability during storage. J. Amer. Soc. Hort. Sci. 103:137-141.

Kelly, K.L. 1965. ISCC-NBS color name charts illustrated with Centroid colors. Standard sample \#2106 Suppl. to Nalt. Bur. Standards Circ. 553. U.S. Govt. Printing Office, Washington, D.C.

Kelly, K.L. and D.B. Judd. 1955. The ISCC-NBS method of designating colors and a dictionary of color names. Natl. Bur. Standards Circ. 553. U.S. Govt. Printing Office, Washington, D.C.

McEachern, G.R., N. Roe, J. Begnaud, J. Janak, and E. Holland. 1994. 1994 Texas pecan grading handbook. TAEX Hort. Hdbk. 102. Tex. A\&M Univ., College Station.

McGuire, R.G. 1992. Reporting of objective color measurements. HortScience 27:1254-1255.

Natioanl Pecan Growers Council. 1980. Federated Pecan Growers'standards for grades of pecans in the shell. Natl. Pecan Growers' Council. Baton Rouge, La. 


\begin{tabular}{|c|c|c|c|c|c|c|c|c|c|}
\hline \multicolumn{5}{|c|}{ Frozen (6 months) } & \multicolumn{5}{|c|}{ Frozen (12 months) } \\
\hline $\mathrm{H}$ & V & $\mathrm{C}$ & $\mathrm{F}$ & $\%$ & $\mathrm{H}$ & V & $\mathrm{C}$ & $\mathrm{F}$ & $\%$ \\
\hline 12.5 & 5 & 4 & 207 & 20.2 & 17.5 & 6 & 4 & 263 & 27.1 \\
\hline 15 & 5 & 4 & 196 & 19.1 & 15 & 6 & 4 & 191 & 19.7 \\
\hline 10 & 5 & 4 & 154 & 15 & 20 & 7 & 4 & 98 & 10.1 \\
\hline 15 & 6 & 4 & 134 & 13.1 & 20 & 6 & 4 & 98 & 10.1 \\
\hline 10 & 5 & 3 & 83 & 8.1 & 15 & 6 & 3 & 80 & 8.3 \\
\hline 10 & 6 & 3 & 35 & 3.4 & 15 & 5 & 4 & 54 & 5.6 \\
\hline 12.5 & 6 & 4 & 33 & 3.2 & 17.5 & 7 & 4 & 28 & 2.9 \\
\hline 12.5 & 4 & 4 & 30 & 2.9 & 17.5 & 5 & 4 & 28 & 2.9 \\
\hline 10 & 4 & 4 & 29 & 2.8 & 20 & 8 & 3 & 21 & 2.2 \\
\hline 15 & 6 & 3 & 16 & 1.6 & 20 & 7 & 3 & 19 & 2 \\
\hline 10 & 4 & 3 & 16 & 1.6 & 20 & 5 & 4 & 15 & 1.5 \\
\hline 10 & 6 & 4 & 15 & 1.5 & 20 & 6 & 6 & 14 & 1.4 \\
\hline 15 & 5 & 3 & 14 & 1.4 & 20 & 6 & 3 & 11 & 1.1 \\
\hline 17.5 & 6 & 4 & 13 & 1.3 & 20 & 8 & 4 & 8 & 0.8 \\
\hline \multirow[t]{3}{*}{17.5} & 7 & 4 & 7 & 0.7 & 17.5 & 6 & 6 & 6 & 0.6 \\
\hline & & & 1,025 & & & & & 969 & \\
\hline & & & & 95.8 & & & & 96.4 & \\
\hline
\end{tabular}

Senter, S.D., W.R. Forbus, Jr., S.O. Nelson, and R.J. Horvat. 1984. Effects of dielectric and steam heating treatments on the pre-storage and storage color characteristics of pecan kernels. J. Food Sci. 49:1532-1534.

Shaw, D.V. 1991 Genetic variation for objective and subjective measures of fresh fruit color in strawberries. J. Amer. Soc. Hort. Sci. 116:894-898.

Soil Survey Division Staff. 1993. Soil Survey Manual. U.S. Dept. Agr.

Hdbk. 18. U.S. Govt. Printing Office, Washington, D.C.

Sugihara, M. 1995. Consistent color. Byte. Jan. p. 93-100. 